\title{
APPLICATION OF A COMPREHENSIVE INFORMATION MANAGEMENT SYSTEM USING GIS AND OA IN HIGHWAY MECHATRONICS MAINTENANCE
}

\author{
Suying Dong \\ Yantai Nanshan University, Yantai, 265713, Shandong, China \\ Email: dongsuyingynu@126.com
}

\begin{abstract}
The aim of this study is to improve the information management efficiency of the highway through the combination of the GIS (Geographic Information System) and OA (Office Automation) in highway mechatronics maintenance. First, the principles and disadvantages of traditional GIS technology are analysed. Then, the COMGIS (Component Object Module GIS) technology is formed through the integration of the GIS and COM (Component Object Module) technology proposed by Microsoft. Finally, a comprehensive information management system for the highway is proposed based on the COMGIS and OA. Next, the proposed system is simulated through an experiment on the mechatronics maintenance of the highway of Hu County of Xi'an in Shaanxi Province. The results show that the user enters the system through the correct user name and password input into the login interface. The shortcut icons in the main interface can be quickly accessed as a common function. Clicking the Map Selection tool can load the selection information in the selection result window. If users perform a fuzzy query, they can find and view detailed map information on the map. The length of the drawn line segment and the polygon surface can be obtained through the distance measurement tool, and the perimeter and area of the graph can be automatically calculated. The manhole condition can be monitored on different highway segments through the system information, which can prompt maintenance personnel timely detection. This shows that the proposed comprehensive information management system for mechatronics maintenance of highways can perform the normal function of both the GIS system and the OA system.
\end{abstract}

Keywords: GIS technology; OA system; Comprehensive Information Management System; Highway; Mechatronics Maintenance.

\section{Introduction}

The developmental history of human society has proved that road transport is essential for the economic and social development of a country or region, and is one of the important driving forces to promote human economic development and social progress. The highway as a road transport has won widespread praise because of its characteristics, such as high speed, safety, and comfort. Highway facilities and traffic engineering research play very important roles in achieving these characteristics $[1,2]$. Highway mechatronics engineering is an inseparable part of highway traffic engineering. Highway mechatronics engineering includes a monitoring system, charging system, communication system, and power supply and distribution lighting system. A high-speed, safe, and comfortable highway cannot be built without highway mechatronics engineering which ensures the normal operation of the highway $[3,4]$. Mechatronics engineering involves many technologies, including mechanics, electronics, monitoring, communication, and computer technology. Meanwhile, miscellaneous equipment is being utilized, which are all very professional and contain high technological standards. There are many problems during maintenance, such as the wide distribution of equipment, wide range of maintenance, poor environmental conditions, high failure rate of equipment, tight maintenance time, and short equipment replacement cycle. Unified and standardized equipment management is urgently needed in the mechatronics engineering of highways for normal operation and improved maintenance of highways $[5,6]$.

The 1990s has witnessed the high-speed development of highways in China. In particular, some remarkable achievements have been gained during China's 11th Five-Year Plan: the total mileage of the highway has increased to more than 70,000 kilometres from over 40,000 kilometres. During the 
tenth Five-Year Plan more than $30,000 \mathrm{~km}$ of the highway have been constructed, creating a unique miracle in the world [7]. With the rapid construction of highways, the mechatronics system is also developing [8]. Besides, the mechatronics system is being perfected with accumulated experience, new technologies, and new equipment, such as solar power supply, contactless IC (Integrated Circuit) card, dynamic weighing, license plate identification, event detection, and digital transmission [9]. However, there are also some problems in the development process, such as the backward management methods of mechatronics maintenance, the lack of unified standard management and maintenance system, and the lack of consistency and effectiveness of data management. Maintenance records are mostly manual records and some necessary forms are prepared. The records are cumbersome and the record formats are not uniformed. Manual records and forms cost much manpower and time. Meanwhile, the retrieval, query, and statistics of these data are very inconvenient and cannot provide more guidance for maintenance management $[10,11]$. The current maintenance management field in foreign countries is in the MIS (Management Information System) stage that integrates the GIS (Geographic Information System) and OA (Office Automation) technologies. The integration of GIS and OA technologies can only be realized through the same system with the same database storage [12]. GIS technology can automate office works and strengthen data maintenance. Comparatively, China is still in the exploration stage. The main technical difficulties can be summed up as follows. The mechatronics equipment of the highway runs 24 hours, the equipment is updated quickly, and the operation and maintenance work are very heavy, which leads to the imperfect information acquisition of the mechatronics equipment. Besides, no technical support is available for the implementation of the formulated equipment management system. The management of the mechatronics system must be based on all relevant information of mechatronics equipment $[13,14]$.

Consequently, to meet the needs of highway management and solve practical problems through informatization, the highway mechatronics information management system is introduced based on a special communication network utilizing GIS and database development technology. As a result, scientific and technical management services are provided for highway mechatronics maintenance. To improve management and maintenance performance and efficiency, the work efficiency and emergency response-ability should be enhanced and service quality should be strengthened. Meanwhile, resources should be allocated reasonably, and expenditure should be reduced.
According to the COMGIS (Component Object Module GIS) and OA system, a comprehensive information management system is proposed for highway mechatronics maintenance. The system is divided into six modules and has perfect functions, which provide feasible strategies for highway mechatronics maintenance.

\section{Design of Comprehensive Information Management System based on New GIS and $0 A$}

\subsection{New Generation GIS Technology}

The transferability of traditional GIS (Geographic Information System) is poor. It is mainly developed for an independent closed system with specific needs. While new system development is timeconsuming and laborious. Meanwhile, the functions of GIS software are becoming increasingly comprehensive, and the traditional GIS development method can no longer develop such a complex system. This has inevitably hindered the popularization and application of GIS [15]. Component software has laid the foundation of new generation GIS. The COMGIS (Component Object Module GIS) can provide a new solution for the development of GIS. The core of GIS is GIS software. The development of GIS software is closely related to IT (Internet Technology) technology, especially, the development of mainstream software technology. Before the emergence of component technology, GIS software is developed through the desktop GIS and special secondary development language. It is difficult for users to learn and use, and it cannot be expanded or integrated with MIS (Management Information System) [16]. GIS systems are only used in a few departments, such as surveying, mapping, and land. It cannot serve more areas in industries or the public. GIS is in the stage of expert GIS. In the 1990s, Microsoft launched COM (Component Object Module) component technology, which has been widely used in GIS software development. The COMGIS is formed through the combination of object-oriented technology and component technology. COMGIS has many advantages, such as high efficiency, seamless integration, and low cost. Moreover, it does not need specialized GIS development language, and it is a programmable and reusable component software $[17,18]$. Consequently, the GIS has begun to integrate into the mainstream of IT and enters the COMGIS stage.

First, the COMGIS (Component Object Module GIS) is explained. The COMGIS can divide GIS function modules into several different controls. Each control performs different functions. Controls are like a bunch of different building blocks, realizing different GIS functions [19]. These building blocks can be allocated accordingly. All GIS controls can be 
combined or integrated with external controls through visual software development tools for an overall GIS application system. COM is a component object model, which is the common foundation of OLE (Object Linking and Embedding) and ActiveX [20]. The traditional GIS tool software will eventually be componentized, and model componentization will become the main way of application model development.

A reusable model component library can be made through the component model, which is the development direction of software reuse technology. As a result, a new technical means is provided for the integration of GIS and the application model.

Then, the characteristics and advantages of COMGIS are introduced from the following six aspects, as shown in table 1.

Table 1 Characteristics of COMGIS

\begin{tabular}{|c|l|}
\hline Characteristics & \multicolumn{1}{|c|}{ Main content } \\
\hline Assemblablity & $\begin{array}{l}\text { System development is the process of assembling various GIS components, which is } \\
\text { also a way of reuse. }\end{array}$ \\
\hline Encapsulation & $\begin{array}{l}\text { Encapsulation can hide design and implementation details so that components } \\
\text { present relatively independent entities. Meanwhile, it can improve the reusability of } \\
\text { components. Complex professional applications such as GIS should attract more } \\
\text { attention. }\end{array}$ \\
\hline Reusability & $\begin{array}{l}\text { It is the basic feature of component software and the initial driving force of the } \\
\text { combination of component technology and GIS technology. Compared with } \\
\text { traditional reuse technologies (Code Segment Reuse and Class Reuse), component } \\
\text { reuse strengthens the compatibility and the convenience of the software [21]. It } \\
\text { emphasizes the reuse of components in professional application fields and combines } \\
\text { them with the reusable components in non-computer fields. }\end{array}$ \\
\hline $\begin{array}{c}\text { Seamless } \\
\text { integration }\end{array}$ & $\begin{array}{l}\text { GIS components with different functions developed in different languages can be } \\
\text { integrated into the same standard development environment. Moreover, GIS } \\
\text { components can also be integrated with other professional applications efficiently } \\
\text { and seamlessly, which reduces the cost of GIS development and provides strong } \\
\text { support for the promotion of GIS. }\end{array}$ \\
\hline $\begin{array}{c}\text { Convenience } \\
\text { programming } \\
\text { language }\end{array}$ & $\begin{array}{l}\text { traditional GIS development. General standard development language can develop } \\
\text { GIS. }\end{array}$ \\
\hline
\end{tabular}

Compared with traditional GIS, COMGIS has the following advantages, as shown in table 2.

Table 2 Advantages of COMGIS

\begin{tabular}{|c|l|}
\hline $\begin{array}{c}\text { Advantages } \\
\text { flexpact and }\end{array}$ & $\begin{array}{l}\text { Main content } \\
\text { The system is compact and flexible and can be connected with the database system. } \\
\text { Its price is only one-tenth of that of traditional GIS development tools [22]. Users } \\
\text { can develop a high-performance GIS system }\end{array}$ \\
\hline Easy to develop & $\begin{array}{l}\text { GIS components can be directly embedded into MIS development tools, developers } \\
\text { can freely choose familiar development tools. Moreover, the interface of GIS } \\
\text { components is very close to that of MIS tools, and developers can skilfully manage } \\
\text { spatial data, such as maps, without training. }\end{array}$ \\
\hline $\begin{array}{c}\text { Stronger } \\
\text { adaptability }\end{array}$ & $\begin{array}{l}\text { Component technology enables ordinary users to develop and integrate GIS } \\
\text { application systems through GIS controls just like ordinary ActiveX controls. } \\
\text { COMGIS is a professional analysis tool for experts and is also a visualization tool for } \\
\text { ordinary users to manage geographic information data, which promotes the } \\
\text { popularization of GIS. }\end{array}$ \\
\hline
\end{tabular}

Lastly, the development method based on the Web (World Wide Web) is proposed. Both COMGIS and WebGIS can be developed through the combination of network technology and COMGIS technology. Browsers can zoom in, move, and select images. The basic functions of GIS are realized through B/S (Browser/Server) structure. Here, the proposed system is a combination of MIS and GIS. During the system development, the latest $\mathrm{B} / \mathrm{S}$ structure will be chosen except for some graphic detail operations.

\subsection{Comprehensive Information Management System based on New GIS and OA}

At present, the domestic highway maintenance information management system is widely used, while the pavement and bridge maintenance 
management system, mechatronics maintenance management system is relatively less. Moreover, the implementation technology is obsolete, which cannot adapt to the changes of business requirements or achieve information sharing. Based on the functional advantages of new GIS and OA, a new system is proposed to store and manage spatial data and business data. The $\mathrm{B} / \mathrm{S}$ structure is adopted to provide an integrated application environment for managers.

OA system refers to the daily maintenance of information centre and system management, including maintenance project, fault repair, equipment management, and document exchange [23]. The key to new system development is to integrate GIS and OA technologies into the same system and store them in the same database. Consequently, the B/S structure based on integrated graphic-text can be provided to each level of managers. During new system development, GIS, OA, and Workflow technologies are integrated to design graphics and text, as shown in figure 1.

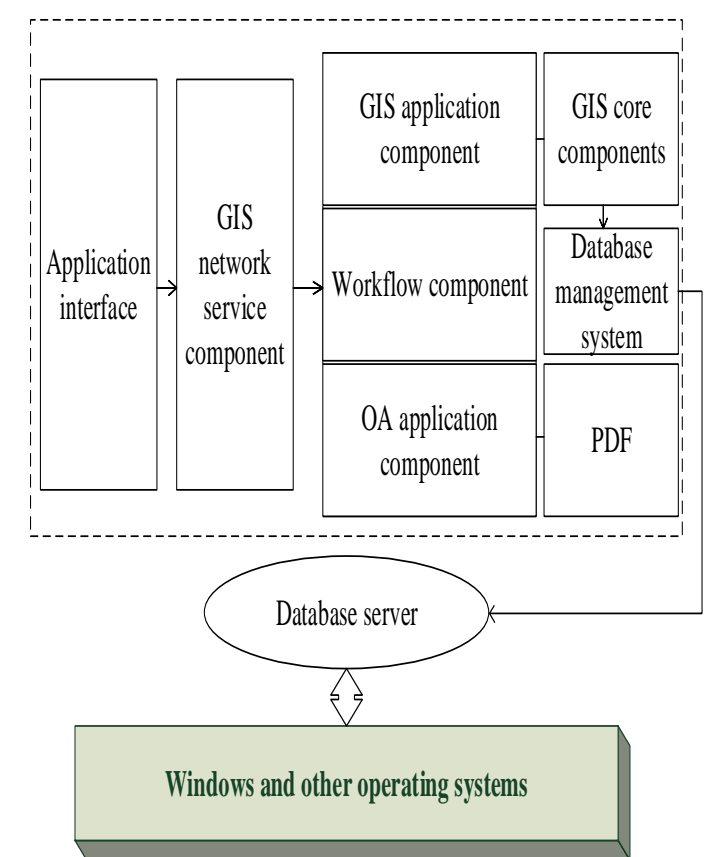

Figure 1: Comprehensive information management system of highway mechatronics

In the above system, business processes, including GIS and OA are defined as an automatic workflow in the computer application environment. The system can automatically transfer documents, information, and tasks among multiple participants according to certain predefined rules to achieve the expected business goal. In this system, the workflow is a series of business activities or tasks connected and executed automatically. The workflow consists of a set of tasks and their order relations. It also includes the start and end conditions of processes and tasks (or activities), as well as the description of each task. The best way to integrate GIS, OA, and workflow technology is to use a full COMGIS development platform. The system encapsulates GIS data input, editing, processing, query display, analysis, and mapping output into components to form GIS components. Users can embed components into web pages and customize the operation mode accordingly. The combination of component technology and web development technology can meet the needs of user business processing and enhances the reusability of software.

The system is designed with an integrated software mode, which can be divided into data service layers, application logic layer, and presentation layer. The data service layer is a database server. According to their usage, they can be divided into attribute data, document data, spatial data, and release data. The application logic layer consists of a variety of application components with different system functions. The component has good reusability and can upgrade and add new interfaces independently without affecting the original system. Besides, components can build new application subsystems. The third layer is the presentation layer, presenting the user interface. The application subsystems will be categorized by the business function and organization structure. The system tools can help the management personnel to visit the list of personnel, check the progress of special projects, and check the use of equipment in each station area. With the system tools, the mechatronics maintenance personnel can report the unhandled equipment faults timely, and the mechatronics management department can reply in real-time. Subsequently, the technicians can quickly go to the site to solve the problems. The system can provide a simple and effective scheduling method for these daily operations. Users can switch from map, form, and document management tools at will for the information interconnection management of map, text, and table integration. The software design is shown in figure 2 .

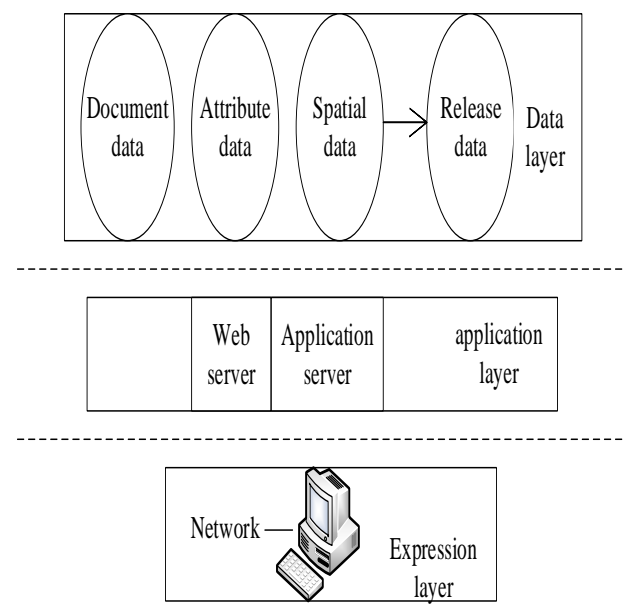

Figure 2: Software components 
GIS retrieves information through the publication of electronic maps on the Internet. It includes a basic map operation function and map query function $[24,25]$. The functional requirements of the system include map amplification, map reduction, full map display, map translation, map selection query, layer control, and legend display. The specific functions and information analysis processes are shown in table 3 and figure 3.

Table 3 Basic functions of the GIS map

\begin{tabular}{|c|l|}
\hline \multicolumn{1}{c}{ Function types } & \multicolumn{1}{c}{ Main content } \\
\hline $\begin{array}{c}\text { Operation } \\
\text { function }\end{array}$ & $\begin{array}{l}\text { Mouse event input, map } \\
\text { display, map zoom, roaming, } \\
\text { full map display, and } \\
\text { navigation }\end{array}$ \\
\hline Query function & $\begin{array}{l}\text { Map click query and select } \\
\text { object list }\end{array}$ \\
\hline Map & $\begin{array}{l}\text { Measurements of positions } \\
\text { between points, linear and }\end{array}$ \\
& $\begin{array}{l}\text { cumulative distances between } \\
\text { points, and perimeter and } \\
\text { area of surfaces }\end{array}$ \\
\hline Editing \\
function & $\begin{array}{l}\text { Equipment adding, deleting, } \\
\text { and replacing. Equipment } \\
\text { location change, location } \\
\text { information input, and cable } \\
\text { information input. }\end{array}$ \\
\hline
\end{tabular}

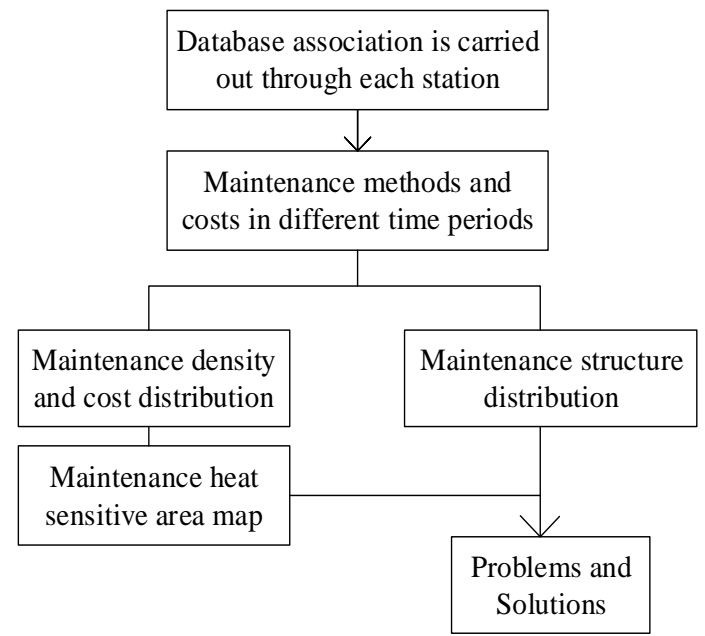

Figure 3: Information analysis steps

\subsection{Design Tool of the Simulation Experiment}

(1) Here, the highway in Hu County of the city of Xi'an, in Shaanxi Province is simulated through experiment. Mechatronics maintenance management system involves spatial data and attributes data of regional equipment. The measurement data and system coverage are very huge. The stability of the system must be considered, as well as the advancement of the platform and the scalability of the later operation. Consequently, the GIS of ESRI
(Environmental Systems Research Institute, Inc.) is utilized together with ArcGIS series software as the GIS platform of the mechatronics maintenance management system, and the .NET Framework is chosen for system development and deployment. The main design tools are shown in table 4 .

Table 4 Developmental tools involved in the system

\begin{tabular}{|c|c|}
\hline Tool type & Name \\
\hline $\begin{array}{c}\text { Database design } \\
\text { tool }\end{array}$ & Powerdesign9.0 \\
\hline $\begin{array}{c}\text { System } \\
\text { development } \\
\text { structure }\end{array}$ & B/S structure \\
\hline GIS platform & ArcGIS series software \\
\hline
\end{tabular}

(2) The Origin 2018 64Bit is utilized for data visualization.

\section{Results and Discussion}

3.1 System Implementation and Interface Display

The login and homepage interfaces of the system are shown in figures $4 \mathrm{~A}$ and $4 \mathrm{~B}$.

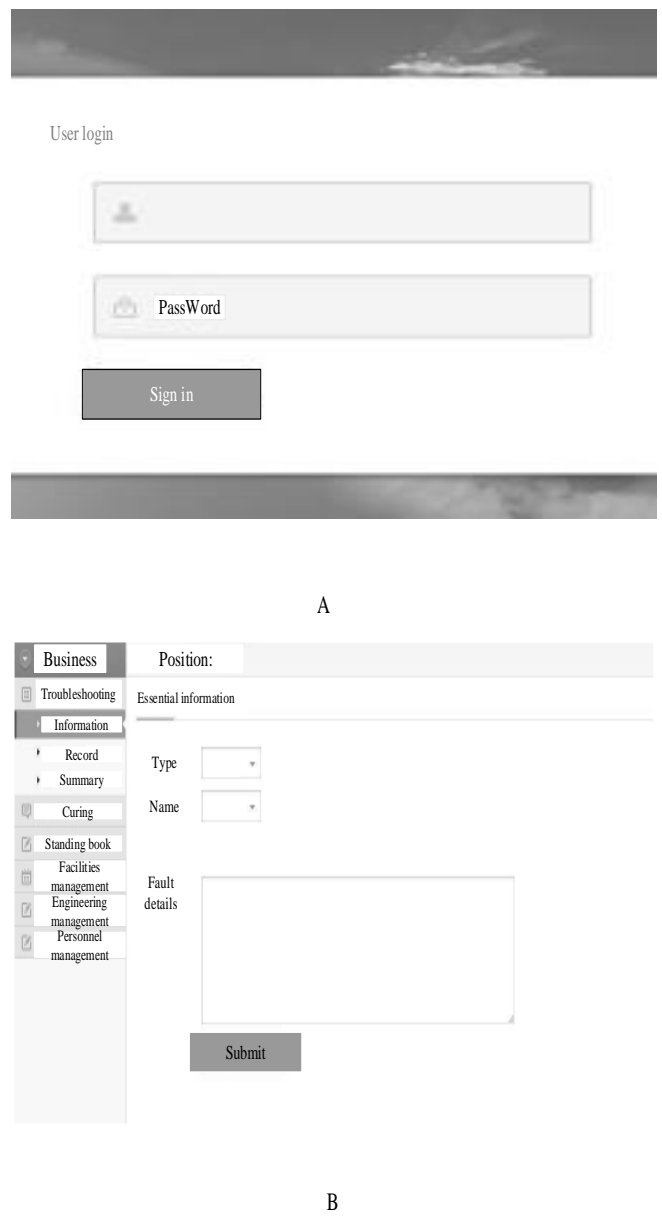

Figure 4: System implementation (A: Login interface B: Homepage) 
Figure 4 illustrates that the user enters the system through the correct username and password input into the login interface. There are six shortcut icons at the top of the homepage, which are fault maintenance, equipment maintenance, account management, equipment component management, engineering management, and personnel information management. These icons can provide quick access to common functions. On the left side below is the navigation list classified through business modules. When the navigation list is clicked, the corresponding page will be displayed on the right. The system interface is displayed through the business module.

\subsection{Realization of Map Retrieval Function of the System}

The proposed system can realize the map retrieval function, as shown in figures $5 \mathrm{~A}$ and $5 \mathrm{~B}$.

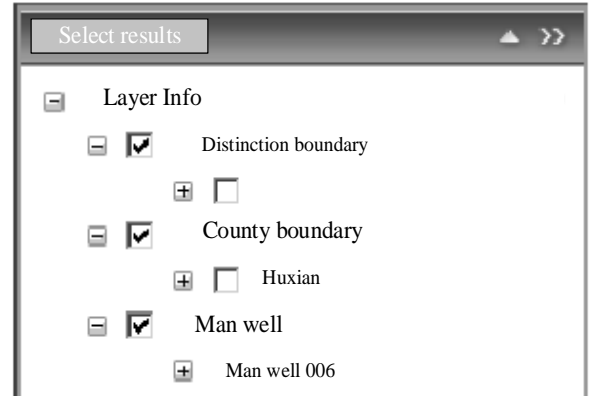

A

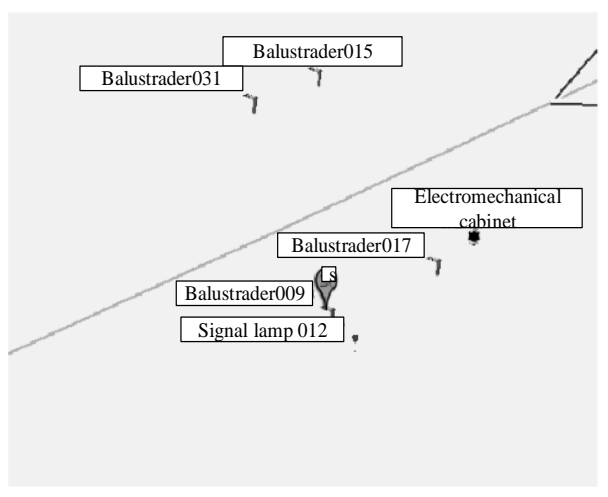

B

Figure 5: System map retrieval and positioning (A: Layer selection B: Positioning)

Obviously, to view the device information, first, the users have to click the map selection tool, then select the device to view in the map, load the selection information in the selection result window, and click the name of the device. If the fuzzy query is executed, rail can be entered in the name box for a fuzzy query. The query results are all the records with rail in the device name, and the detailed map information can be viewed.

\subsection{Realization of the Mapping Function}

The proposed system can realize the mapping function, as shown in figures $6 \mathrm{~A}, 6 \mathrm{~B}$, and $6 \mathrm{C}$.
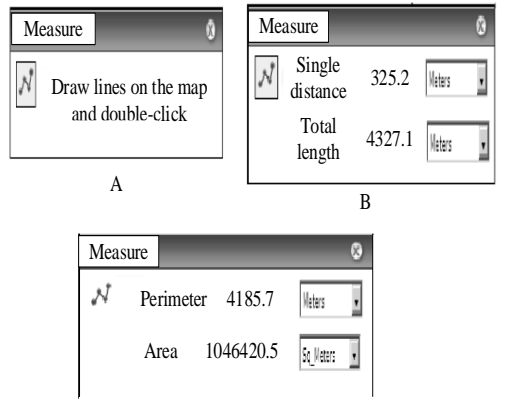

c

Figure 6 Mapping function (A: Draw straight lines or broken lines B: Line length C: Perimeter and area)

Figures $6 \mathrm{~A}$ and $6 \mathrm{~B}$ illustrate that to obtain the length of a drawn line segment, users can select the distance measurement tool, with the operation tips below the tool, then draw straight lines or broken lines on the map, and double-click to complete the operation. Figure 6C shows that to obtain the perimeter and area of the screen, users can select the face-to-face measurement tool, with the operation hint below the tool, then draw a polygon surface on the map, and double-click to complete the operation.

\subsection{Specific Information of System Simulation Experiment}

Here, the mapping equipment information and manholes information collected by the system are analysed. Map equipment information is shown in figure 7
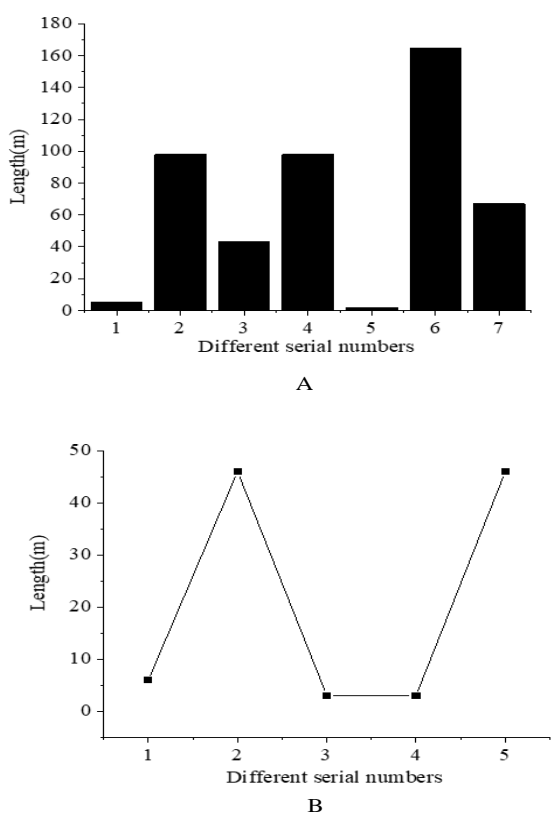

Figure 7: System map information (A: Map equipment information B: Map layer information) 
Figure 7A shows that the measurement length of map equipment with different serial numbers varies greatly. The maximum measured value is about $165 \mathrm{~m}$, while the minimum measurement value is about $2 \mathrm{~m}$. Figure 7B indicates that the difference of map layer information of different serial numbers is smaller than that of map equipment. The maximum length is about $45 \mathrm{~m}$, while the minimum length is about 3M.

The information of the manhole is shown in figure 8.

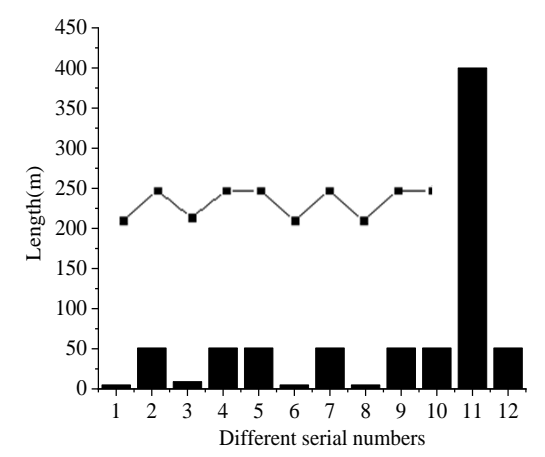

Figure 8: Manholes information map

Figure 8 shows that the values of manholes information in the first 10 sequences change very slightly, they all change between [5,51], and there is a specific period (1-4 and 6-9) as shown in the broken line. While from the tenth serial number, the value fluctuates dramatically, from as high as $400 \mathrm{~m}$ at the eleventh serial number to $51 \mathrm{~m}$ at the 12 th serial number. This implies that there is an abnormal situation at the 10th serial number, which needs to be checked.

\section{Conclusion}

The purpose is to solve the technical problems encountered in highway management. Based on the principle of GIS and OA, the comprehensive information management system of the highway is proposed. The system can carry out fault maintenance, equipment maintenance, account management, equipment component management, engineering management, and personnel information management. The system simulation experiment and data visualization analysis show that the user enters the system through the correct username and password input into the login interface. There are six shortcut icons at the top of the homepage, which can access common functions quickly. To view the device information and detailed map information, the user can click the map selection tool, then select the device to view in the map, load the selection information in the selection result window, and click the device name. The measurement length of map equipment with different serial numbers varies greatly. While the difference between the map layer information of different serial numbers is smaller than that of the mapping equipment. The information of manhole has a specific period in the first 10 different sequences. But from the tenth serial number, the value fluctuates dramatically, indicating that there is an abnormal situation. There are some shortcomings. First, the research and analysis of the system are not comprehensive enough. For example, more scientific analysis methods should be adopted for various equipment, which can provide a decision basis to meet different requirements. Second, the system functions are not perfect. To be specific, a mobile phone client can also be designed for the proposed system, which can support inspectors and maintenance personnel to access the system, report faults, fill in logs, and even take photos. This is also the key content of the next research plan.

\section{References}

[1] García Carmelo, Alexis Q A, Cristóbal Teresa, et al. (2016) Systematic Development of Intelligent Systems for Public Road Transport. Sensors (14248220), 16(7), 1-23.

[2] Emonts B, Schiebahn S, Gorner K, et al. (2017) Reenergizing energy supply: Electrolyticallyproduced hydrogen as a flexible energy storage medium and fuel for road transport. Journal of Power Sources, 342(FEB.28), 320-326.

[3] Jakubas A, Chyra M, Gnatowski A. (2019) The Influence of Reinforcement Fibers on Mechanical and Electrical Properties of the Electrical Engineering Composites. Acta Physica Polonica A, 135(2), 193-195.

[4] Kowalczyk S, Zawrzykraj P, Malakowski M. (2017) Application of the electrical resistivity method in assessing soil for the foundation of bridge structures: A case study from the Warsaw environs, Poland. Acta Geodynamica et Geomaterialia, 14(2), 221-234.

[5] Ye W, Guo Y, Liang R, et al. (2020) Research on Thermo-Mechanical Coupling Deformation for the Ball Screw of Machine Tool Spindle Feed System. Journal of Vibration Engineering \& Technologies, 8(3), 443-454.

[6] Oda T, Aziz M, Mitani T, et al. (2017) Actual Congestion and Effect of Charger Addition in the Quick Charger Station: Case Study Based on the Records of Highway. Electrical Engineering in Japan, 198(2), 11-18.

[7] Yonggang, Wang, Longjian, et al. (2016) How eye movement and driving performance vary before, during, and after entering a long expressway tunnel: considering the differences of novice and experienced drivers under daytime and nighttime conditions. SpringerPlus, 5(1), 538-538.

[8] Worakan H, Yanin H, Du?Ko D, et al. (2018) Dependence of mechanical and electrical 
properties of silver nanocubes impregnated bacterial cellulose-silk fibroin-polyvinyl alcohol films on light exposure. Polymer Testing, 71, 110114.

[9] Qasrawi A F, Kmail R R N, Mergen A, et al. (2016) Mechanical and electrical properties of Bi1.5-xLaxZn0.92Nb1.506.92 pyrochlore ceramics. Journal of Electroceramics, 37(1-4), 814.

[10] Durairaj R, Pheng L S, Ping L J. (2016) Investigation on the mechanical and electrical properties of multiwall carbon nanotubes (MWNCTs) based isotropic conductive adhesives. Pigment and Resin Technology, 45(4), 240-245.

[11] Queiruga A F, Zohdi T I. (2016) Microscale Modeling of Effective Mechanical and Electrical Properties of Textiles: Microscale Modeling of Electrical Properties of Textiles. International Journal for Numerical Methods in Engineering, 108(13), 1603-1625.

[12] Zhu J, Wang X, Wang P, et al. (2019) Integration of BIM and GIS: Geometry from IFC to shapefile using open-source technology. Automation in Construction, 102(JUN.), 105-119.

[13] Zhao Z, Feng J. (2019) Spatio-temporal analysis of land use changes using remote sensing in Horqin sandy land, China. Sensor Review, 39(6), 844-856.

[14] Luo F, Wei W, Wang C, et al. (2016) Research and application of GIS-based medium-voltage distribution network comprehensive technical evaluation system. International Transactions on Electrical Energy Systems, 25(11), 2674-2684.

[15] Ciabocco M, Berrettoni M, Zamponi S, et al. (2016) A Spatial Analytic Hierarchy Process for Identification of Water Pollution with GIS Software in an Eco-Economy Environment. Journal of Solid State Electrochemistry, 20(5), 1323-1329.

[16] Saint-Martin C, Javelle P, Vinet F. (2018) DamaGIS: A multisource geodatabase for collection of flood-related damage data. Earth System Science Data, 10(2), 1019-1029.
[17] Vukasinovic V, Gordic D. (2016) Optimization and GIS-based combined approach for the determination of the most cost-effective investments in biomass sector. Applied Energy, 178(sep.15), 250-259.

[18] Barnett A J, Wiber M G, Rooney M P, et al. (2016) The role of public participation GIS (PPGIS) and fishermen's perceptions of risk in marine debris mitigation in the Bay of Fundy, Canada. Ocean \& Coastal Management, 133(Dec.), 85-94.

[19] Rossella A, Carlotta G, Simona Q, et al. (2017) The Influence of the Framework and Extraframework Content on the High Pressure Behavior of the GIS Type Zeolites: The Case of Amicite. Minerals (2075-163X), 7(2), 1-16.

[20] Sokas, Algirdas. (2017) Graphical Methods for Designing Bolted Joints in Engineering Drawings. Procedia Engineering, 172(Complete), 10441052.

[21] Zhou J, Feng K, Pei Z, et al. (2016) Multivariate analysis combined with GIS to source identification of heavy metals in soils around an abandoned industrial area, Eastern China. Ecotoxicology, 25(2), 380-388.

[22] Kelly M R, Kostyrko K, Han K, et al. (2020) Combined Proteomic and Genetic Interaction Mapping Reveals New RAS Effector Pathways and Susceptibilities. Cancer Discovery, 10(12), CD-191274.

[23] Haiyun X, Xiao F. (2016) Design of Digital Campus Office Automation System Based on Portlet and Workflow. International Journal of Smart Home, 10(6), 321-328.

[24] Gurin I A, Lavrovet V V, et al. (2017) Web technology in automated information and modeling systems for metallurgical processes. Steel in Translation, 47(7), 463-468.

[25] Bui D T, Hoang N D. (2017) A Bayesian framework based on a Gaussian mixture model and radial-basis-function Fisher discriminant analysis (BayGmmKda V1.1) for spatial prediction of floods[J]. Geoscientific Model Development, 10(9), 1-19. 